\title{
O DIREITO ADMINISTRATIVO SOBREVIVERÁ À GLOBALIZAÇÃO? UM DIÁLOGO ENTRE OS PRINCÍPIOS CONSTITUCIONAIS E A REVOLUÇÃO VIRTUAL
}

\author{
WILL ADMINISTRATIVE LAW SURVIVE GLOBALIZATION? \\ A DIALOGUE BETWEEN CONSTITUTIONAL PRINCIPLES AND \\ THE VIRTUAL REVOLUTION
}

\author{
José Laurindo de Souza Netto ${ }^{1}$ \\ Adriane Garcel ${ }^{2}$ \\ Lucas Damakoski Cordeiro ${ }^{3}$
}

\begin{abstract}
RESUMO
O objetivo deste artigo é investigar o futuro do direito administrativo ante a globalização. Diante do descompasso entre a revolução tecnológica e a natureza lenta do aparato estatal, a problemática consiste em verificar se a Lei 12.965/14, Marco Civil do uso da Internet no Brasil, foi capaz de incorporar determinados princípios constitucionais, administrativos e fomentar uma maior intervenção estatal no ambiente virtual. A pesquisa justifica-se tendo em vista a escassa previsão legislativa sobre o tema e a forma como a revolução virtual impactou de forma indelével as relações sociais. A metodologia utilizada baseia-se em uma análise doutrinária, legislativa e quantitativa. Por conclusão, o Estado deverá incorporar de forma positiva as novas ferramentas erigidas pelo advento da internet, em favor da sociedade, cabendo ao legislador encontrar o equilíbrio entre o interesse coletivo e o direito à privacidade.
\end{abstract}

Palavras-chave: Direito Administrativo. Revolução Virtual. Intervenção Estatal. Marco Civil da Internet. Princípios Constitucionais.

\footnotetext{
ABSTRACT

The purpose of this article is to investigate the future of administrative law in face of globalization. In view of the mismatch between the technological revolution and the slow nature of the State apparatus, the problem is to verify whether Law 12.965 / 14, Civil

1 Pós-doutor pela Faculdade de Direito da Universidade Degli Studi di Roma - La Sapienza. Estágio de Pósdoutorado em Portugal. Professor permanente no Mestrado da Universidade Paranaense - UNIPAR. Desembargador, $2^{\circ}$ Vice-Presidente, membro do Órgão Especial e Presidente do NUPEMEC do Tribunal de Justiça do Paraná.

2 Mestranda em Direito Empresarial e Cidadania no Centro Universitário de Curitiba - UNICURITIBA. Pesquisadora no grupo de pesquisa: Crise da Jurisdição e mercado: efetividade e plenitude institucional; Direito Penal Econômico: repercussões interdisciplinares na política-criminal econômica e impactos nas categorias dogmáticas do delito e da pena; Compliance - Registrados no CNPq. Mediadora Judicial. Assessora Jurídica do Tribunal de Justiça do Estado do Paraná.

${ }^{3}$ Graduando do curso de História - Licenciatura e Bacharelado da Universidade Federal do Paraná (UFPR).
} 
Framework for the use of the Internet in Brazil, was able to incorporate certain constitutional, administrative principles and encourage State intervention in the virtual environment. The research is justified in view of the scarce legislative provision on the subject and the way in which the virtual revolution has impacted social relations. The methodology used is based on doctrinal, legislative and quantitative analysis. In conclusion, the State should positively incorporate the new tools created by the advent of the internet, in favor of society, and it is up to the legislator to find the balance between the collective interest and the right to privacy.

Keywords: Administrative law. Virtual revolution. State Intervention. Civil internet framework. Constitutional principles.

\section{INTRODUÇÃO}

“As rodas da máquina têm de girar constantemente, mas não podem fazê-lo se não houver quem delas cuide. É preciso que haja homens para cuidar delas, homens tão constantes como as rodas nos seus eixos, homens sãos de espírito, obedientes, satisfeitos em sua estabilidade" (HUXLEY, 1996, p.43).

A Administração Pública se encontra, evidentemente, em descompasso com um mundo que atravessa uma plena revolução global e virtual, estando atrasada em relação às inúmeras inovações que estão a rapidamente alterar o tecido social. Sua natureza lenta e ponderada, típica do aparato estatal, demora para absorver novidades, fazendo com que o desequilíbrio seja sentido principalmente quando certas estruturas arcaicas do Estado se deparam não apenas com as inovações que se disseminam a olhos vistos, mas também com uma nova geração que nasceu e cresceu em meio à tecnologia. Assim como Linda, a personagem de Huxley que se encontra em um limbo entre dois mundos, sem conseguir se adaptar a nenhum deles, a Administração encontra-se no limbo entre o passado e o presente, arrastada pelas pesadas estruturas herdadas do passado e despida dos necessários valores e aparatos para o presente.

Nesse sentido, um dos primeiros passos do Estado na regulação da arena virtual foi a Lei do Marco Civil da Internet, que iniciou, ainda que de forma tardia, a participação do Estado nas discussões desta seara.

A Lei do Marco Civil da Internet (Lei 12.965/14) surgiu com o objetivo de regular a utilização da internet no Brasil, delimitando direitos e deveres do usuário e estabelecendo princípios próprios relativos ao avanço da comunicação virtual no século XXI. Dada a quase inexistência, no Brasil, de previsão legal focada nos novos meios de comunicação e relações sociais, a Lei teve relevância por surgir em um momento de transição, inaugurado pelo acesso 
massificado à comunicação praticamente instantânea, às novas percepções de mundo e aos inevitáveis desdobramentos, no mundo real, de questões que cada vez mais se desenvolvem em âmbito virtual.

A falta de dispositivos legais que lidem com a nova realidade trazida pelo acesso massificado à internet traz em seu bojo, também, algumas dificuldades e questionamentos, principalmente relativos ao empreendedorismo e à livre-iniciativa virtuais, à proteção de dados dos usuários - que alimentam, a cada minuto, servidores do mundo todo com milhões de dados sigilosos, bancários e pessoais - e concernentes aos limites entre direitos e deveres do usuário do sistema.

Relevante, também, é a possibilidade do uso da tecnologia e da internet pela Administração Pública, de forma a contribuir para a publicidade de seus atos e para a disponibilidade de serviços à população em geral. Nesse sentido, a despeito de um uso crescente dos meios virtuais, os órgãos públicos ainda se utilizam de forma tímida deste novo expediente, carecendo de diretrizes mais claras e de uma postura mais inovadora para o aproveitamento das amplas ferramentas à disposição.

Por outro lado, o surgimento e a consolidação da Big Tech, termo utilizado para descrever o conglomerado de gigantescas companhias de tecnologia e internet surgidas a princípio no Vale do Silício que, hoje, dominam diversos setores do mercado mundial, contribuiu para uma mudança definitiva em todos os níveis das relações sociais, influenciando desde questões de Direito Internacional - com caso notório sendo a guerra comercial travada entre Estados Unidos e China, por exemplo, que levou ao banimento, nos EUA, da gigante chinesa de tecnologia Huawei - até pequenas questões do dia-a-dia da população.

O modelo da Big Tech, revolucionário, de busca constante por inovação e de crescimento acelerado, contribuiu para o surgimento de diversas outras iniciativas que alteraram fundamentalmente o estilo de vida de boa parte da sociedade, como revela o uso massivo dos aplicativos de serviços e dos novos modelos de bancos e créditos virtuais que deram acesso a comodidades antes inimagináveis: mudou o mercado, mudaram as relações pessoais e mudaram, também, as relações de consumo. Segundo Viana (2018, p.3-4):

Há quem diga que as novas tecnologias trazem a mesma inovação que os veículos a motor, invenção de telefone ou máquinas que deram início à Revolução Industrial (...). Por outro lado, é incontroverso que se está diante de uma nova realidade virtual que muda de maneira rápida. Essa é a razão pela qual Klaus Schwab, Diretor Executivo do Fórum Econômico Mundial, acredita que se trata de transição a um novo sistema, alicerçado em um mundo digital, que mudará de modo fundamental o modo que vivemos. 
Em meio a esse panorama extremamente fluido - de mudança constante e instantânea - o Direito possui dificuldades para se adaptar, dado que os processos de construção da ciência jurídica - legais, intelectuais e, também, sociais - caminham a passos lentos e ponderados. Como o Direito Administrativo vem reagindo, então, à extrema fluidez da contemporaneidade permeada pela internet e seus efeitos? Adicionalmente, seria a Lei do Marco Civil uma resposta eficaz às demandas de um novo tempo?

Tendo tais questionamentos em mente, é cabível analisar até que ponto a Lei do Marco Civil da Internet absorveu e contemplou, em seu escopo e previsões, alguns princípios consagrados constitucionalmente, como a liberdade de expressão e o respeito aos Direitos Humanos, bem como os preceitos gerais do Direito Administrativo, como as bases principiológicas da atividade econômica e os princípios da liberdade de iniciativa e da livreconcorrência.

Traçando um diálogo entre a Lei do Marco Civil, entre os artigos atuais sobre a revolução virtual, a obra Direito Administrativo para Céticos, de Carlos Ari Sunfeld e a obra magna de Celso Antônio Bandeira de Mello, seu Curso de Direito Administrativo, particularmente em seu capítulo pertinente à intervenção do Estado nos domínios econômico e social, objetiva-se investigar o alinhamento da Lei $\mathrm{n}^{\mathrm{o}} 12.965 / 14$ ao restante do ordenamento jurídico pátrio, intentando também a analisar brevemente a crucial questão da privacidade dos dados na rede, disciplinada de forma extremamente incipiente pelos diplomas legais existentes no país.

\section{A LEI DO MARCO CIVIL DA INTERNET}

A Lei $\mathrm{n}^{\mathrm{o}}$ 12.965/14 surgiu com o objetivo principal de regular e normatizar determinados aspectos do uso da Internet no Brasil, principalmente relacionados às novas dinâmicas sociais desenvolvidas na arena virtual. Foi aprovada após extensos debates sobre o assunto, instigados pelo artigo Internet Brasileira Precisa de Marco Regulatório Civil, de Ronaldo Lemos, professor da Fundação Getúlio Vargas.

Segundo o autor, o projeto de lei de crimes virtuais do senador Eduardo Azeredo (PSDB-MG), debatido à época, não tratava adequadamente do problema da falta de regulamentação da Internet no Brasil, principalmente por abordar a questão sob um viés estritamente criminal, ao contrário do caminho trilhado por países que já haviam estabelecido marcos regulatórios estritamente civis para o uso da rede. 
Além disso, a lei proposta por Azeredo estabelecia punições demasiado severas para questões como compartilhamento de músicas e arquivos de mídia pela Internet, por exemplo, atos que, de acordo com o projeto de lei, poderiam ser penalizados com até quatro anos de prisão. A lei daria margem, também, à limitação extrema do compartilhamento de arquivos com princípios acadêmicos, o que resultaria em inevitável atraso às atividades de pesquisa e tecnologia no Brasil, restringindo severamente o desenvolvimento de inovação no país, que se dá de forma profundamente colaborativa, principalmente nas universidades, que coordenam suas pesquisas e compartilham estudos, postura necessária ao se constatar o baixo incentivo à pesquisa e desenvolvimento.

Nesse sentido, o projeto de lei resultou em amplos questionamentos por parte da sociedade, principalmente do setor acadêmico, no qual a questão do compartilhamento de dados na rede já vinha sendo discutida há alguns anos; de todo modo, na forma como o projeto estava, o objetivo de combater os crimes virtuais não seria alcançado, e os principais penalizados seriam aqueles que meramente compartilhavam conteúdos diversos na rede. Dessa forma, de acordo com Lemos (2007), a regulação civil deveria vir antes da criminal, pois

(...) para inovar, um país precisa ter regras civis claras, que permitam segurança e previsibilidade nas iniciativas feitas na rede (como investimentos, empresas, arquivos, bancos de dados, serviços, etc). As regras penais devem ser criadas a partir da experiência das regras civis. Isso de cara eleva o custo de investimento no setor e desestimula a criação de iniciativas privadas, públicas e empresariais na área.

A Lei propriamente dita tem suas origens em uma consulta pública feita em 2009 pela Internet. Esse foi um processo pioneiro, dado ter sido a primeira vez que um projeto de lei foi construído com o auxílio da participação popular através da rede e aproveitando as extensas potencialidades - àquela altura já latentes - dos meios virtuais. O projeto em si foi elaborado com o auxílio do Centro de Tecnologia e Sociedade da Fundação Getúlio Vargas do Rio de Janeiro e do Ministério da Justiça, incorporando muitas das sugestões destas entidades e das resultantes discussões em plataformas online.

Uma das principais discussões que circundaram o projeto de lei foi a questão da necessidade ou não de regulação do uso da Internet. Trata-se de questão controversa, dado a Internet ter sido criada com base em princípios de liberdade de uso e expressão. Essa verve foi reforçada principalmente a partir de alguns manifestos emitidos ao longo da década de 90, como a Declaração de Independência do Ciberespaço, de John Perry Barlow (2019), que buscava, através do uso de uma retórica inflamada e que conclamava a liberdade, afastar a 
possibilidade de interferências - de qualquer tipo - no mundo virtual por parte dos Estados, de forma a manter o ambiente da Internet livre de quaisquer limitações, declarando a Internet imune e livre de qualquer soberania.

A garantia da liberdade da Internet contra interferências do Estado estaria, dessa forma, incrustada nos próprios princípios que acompanharam o surgimento da rede. Ao estar livre de quaisquer jurisdições e soberanias, a Internet garantiria, aos usuários, a liberdade total do tráfego de dados, o que implica, necessariamente, na não-discriminação dos conteúdos que trafegam no sistema. Tendo essa questão em vista, ficam evidentes as razões para as grandes controvérsias que cercam o Marco Civil, principalmente no que tange às exceções abertas ao controle da rede.

A interpretação expressa na Lei, no entanto, é a de que a regulamentação existe justamente como garantia à liberdade, questão que ainda resta controversa, a despeito da grande valorização, no texto do diploma legal, da liberdade de expressão. É evidente, no entanto, que a existência de qualquer regulação é questão irreconciliável com os ideais de liberdade total da rede, posto ser uma imposição de regras ao uso do ambiente virtual.

Independentemente dos princípios condutores que levaram à criação do diploma legal, no entanto, sua construção temporal contribuiu para trazer à tona o debate sobre as potencialidades da internet, em uma discussão que já se realizava há alguns anos - ainda que sem nenhuma medida de vulto comparável ao Marco Civil - e que prossegue mesmo após a aprovação da Lei, dadas as inúmeras controvérsias que cercam este diploma legal, que se constituiu, tardiamente, como a primeira iniciativa jurídica de vulto para a Internet brasileira.

$\mathrm{Na}$ medida em que as potencialidades - tanto em sentido positivo quanto negativo - da internet tenham ficado mais claras, é natural o impulso, por parte do Estado, da regulamentação. Pela rede passam, afinal, não apenas novas formas de comunicação e sociabilidades: passam, também, mercadorias, debates políticos, expressões populares, dentre uma infinidade de outras questões que interessam ao ente estatal, seja pelo viés da tributação, seja pela absorção da opinião popular manifestada na rede. A Lei do Marco Civil da Internet se tornou referência, no entanto, justamente por promover a liberdade da rede com base na proteção dos direitos fundamentais, numa construção principiológica que permite a manutenção do diploma legal por um maior período de tempo, como ressalta Lemos (2016, p.16):

Foi com essa motivação que o Marco Civil foi concebido: como uma lei que pudesse preservar as bases para a promoção das liberdades e dos direitos na Internet no Brasil. Distanciando-se assim de uma regulação repressiva da rede, o Brasil ofereceu 
um dos mais simbólicos exemplos (...) sobre uma regulação da rede que tenha os direitos humanos como o seu fio condutor e que mantém o caráter principiológico para evitar uma caducidade de seus dispositivos.

A construção do diploma legal, assentada sobre bases principiológicas, é relevante justamente por conta da natureza do mundo virtual: por suas mudanças repentinas e extremamente ágeis, a Internet rapidamente tornaria obsoleta qualquer lei demasiado prescritiva, baseada puramente numa regulação formal de características funcionais da rede. Ao embasar a lei em questões voltadas aos direitos humanos, o legislador garantiu uma vigência muito mais extensiva do diploma legal, o que elimina - ou, ao menos, mitiga - a provável necessidade de adaptar o código diversas vezes em razão da fluidez verificada na Internet e do acelerado desenvolvimento de novas funções e tecnologias na arena virtual.

A implementação efetiva da Lei se deu através do Decreto 8771/2016, editado após extensas consultas conduzidas por órgãos governamentais, tais como o Ministério da Justiça e a ANATEL. Algumas disposições contidas neste Decreto constituíram os pontos mais controversos do Marco Civil, particularmente no que tange às discussões sobre a neutralidade da rede e o controle de dados dos usuários.

A neutralidade da rede é um preceito basilar da Internet, que indica que o tráfego de dados de um ponto a outro da rede deve ser neutro, ou seja, igualitário, independentemente do conteúdo a ser transmitido, que seria livre e não deveria estar submetido a nenhum tipo de controle prévio; o único controle previsto pelo princípio da neutralidade da rede é aquele que o próprio usuário realiza, na porta em que ele recebe o conteúdo, selecionando aquilo que lhe interessa dentre a multiplicidade de conteúdos possíveis.

O termo neutralidade da rede se popularizou e disseminou a partir de artigo de Tim Wu (2003), professor da Columbia Law School, intitulado Network Neutrality, Broadband Discrimination, que defendeu o estabelecimento de um regime de banda larga por parte das operadoras que controlasse a quantidade de dados, e não sua qualidade, como forma de contribuir para a manutenção da neutralidade da internet. Dessa forma, os provedores não poderiam cobrar por pacotes específicos para conteúdos determinados, mas apenas pela quantidade e velocidade do pacote de dados oferecido, sem prender o consumidor às opções pré-determinadas de conteúdo que o provedor possa querer forçar ao usuário e, consequentemente, sem que o provedor controle arbitrariamente aquilo que o consumidor pode ou não ver e acessar. Segundo Lygia Henrique, o princípio da neutralidade, assim, ao determinar que usuários e conteúdos não possam ser discriminados, empodera o usuário dando a este o controle e a livre escolha (sem qualquer imposição) de qual conteúdo acessar, 
bastando, para tanto, que contrate a quantidade de banda necessária e suficiente aos seus anseios, o que é bom tanto para o mercado, quanto para o consumidor.

A Lei do Marco Civil da Internet protege, no Brasil, a neutralidade do sistema através de seu art. $3^{\circ}$, que a elenca entre os princípios do uso da Internet, determinando também, em seu art. $9^{\circ}$, a proibição de discriminação de conteúdo por parte dos provedores, que devem tratar todos os dados de forma isonômica. Para além da vedação à discriminação de conteúdo, o art. $9^{\circ}$ também trata de proteger a privacidade do usuário, ao vedar, aos provedores, qualquer tipo de monitoramento, filtragem ou análise dos conteúdos dos pacotes de dados utilizados pelos seus clientes.

Relevante ressaltar, no entanto, que - assim como qualquer questão principiológica absorvida pelo ordenamento - o princípio da neutralidade da rede não é absoluto, devendo ser sopesado junto dos princípios que regem a racionalidade do ordenamento jurídico nacional, como a igualdade e a dignidade da pessoa humana, em postura similar àquela adotada pelo constitucionalismo brasileiro, que, adotando as teorias de Robert Alexy (2014), acredita no sopesamento de princípios como medida essencial para se obter os mandados de otimização, que devem ser balanceados para que se obtenha o melhor resultado possível diante das condições fáticas. A busca pela neutralidade, portanto, deve ter em mente não apenas a liberdade do usuário, mas também os limites naturalmente impostos a essa liberdade, como a limitação ao acesso de conteúdos criminosos, por exemplo.

A neutralidade da rede também pode ser interpretada como uma proteção à condição igualitária entre os concorrentes do mercado de telecomunicações, visando a evitar que uma companhia maior que as outras se utilize da rede de comunicações para limitar a atuação da concorrência; segundo Gonçalves, as empresas que detém maior controle sobre as redes e estruturas de comunicação virtual devem se abster de impedir e obstaculizar o acesso e manutenção de concorrentes em suas redes, a fim de gerar competição de mercado benéfica aos consumidores (GONÇALVES, 2017, p. 58).

Subsiste controvérsia, no entanto, em torno do $\S 1^{\circ}$ do art. $9^{\circ}$, que estabelece a competência privativa do Presidente da República para discriminar ou degradar, em determinadas situações, o tráfego de dados na rede, podendo estes atos decorrerem estritamente de requisitos técnicos indispensáveis à prestação adequada dos serviços e aplicações ou da priorização de serviços de emergência.

Dessa forma, fica o regular funcionamento da rede submetido à discricionariedade do titular do Poder Executivo, sendo que os dispositivos que permitem a interferência no fluxo de dados não apontam com clareza quais seriam os pressupostos necessários para essa 
intervenção: o que seriam, no âmbito da Internet, os serviços de emergência? Como se encaixam, nessa prescrição, as redes sociais, que muitas vezes servem como alerta de desastres naturais ou condições perigosas para os seus milhões de usuários? Tais questões dentre inúmeras outras - não são tratadas pelo texto da Lei e permanecem controversas, o que torna demasiado amplos e indefinidos os requisitos para discriminação e degradação da rede através de ação presidencial.

Subsidiariamente, para além da falta de especificidade e de meios concretos de efetivação das prescrições relacionadas à discricionariedade do Poder Executivo, quaisquer regulamentações a mais por parte dele careceriam de efetividade, dado que não será ele o executor destas regulamentações. De acordo com Gonçalves (2017),

\footnotetext{
Pelo que foi exposto, a situação é bem complexa e deveria ser melhor atendida pelo Marco Civil e não por regulamento presidencial. Aliás, regulamento presidencial não é a melhor ferramenta jurídica para normatizar a neutralidade da rede por dois motivos: não há o que regulamentar e, mesmo se houvesse, o regulamento inovaria na esfera legislativa e poderia ir contra o próprio Marco Civil.
}

As controvérsias relativas ao Marco Civil da Internet seguem em debate, inclusive com autores que caracterizam o diploma legal como permeado por aspectos inconstitucionais. Cabe analisar, portanto, em que medida os princípios do Direito Constitucional e do Direito Administrativo foram absorvidos pela Lei, de forma a construir uma compreensão de seu alinhamento no ordenamento jurídico nacional e verificar em que medida estas áreas do Direito estão alinhadas às expectativas para o futuro, principalmente com a crescente entrada da ciência jurídica na seara da tecnologia.

\section{PRINCÍPIOS CONSTITUCIONAIS E ADMINISTRATIVOS NO MARCO CIVIL DA INTERNET E A QUESTÃO DOS DADOS NA REDE}

O princípio basilar da Lei do Marco Civil da Internet é a liberdade de expressão, consagrada logo no Art. $2^{\circ}$ da Lei, que prevê que a disciplina do uso da Internet no Brasil tem como fundamento o respeito à liberdade de expressão. Sendo esse o princípio que o legislador optou por ressaltar logo no caput do artigo, asseverando, inclusive, que o próprio uso da rede em território nacional tem como base a liberdade de expressão, os demais princípios assumem caráter subsidiário, ainda que também possuam relevância, posto que se encontram previstos na Lei. 
Dessa forma, a redação do Marco Civil evidencia a vontade do legislador de garantir o uso da Internet como um fórum para a livre circulação de ideias, o que coincide com um dos próprios princípios fundacionais do sistema, que cresceu justamente com base na possibilidade da livre expressão e do debate.

No que tange aos incisos do Art. $2^{\circ}$, que enumeram princípios subsidiários, fica evidente também o caráter de limitação que eles impõem à liberdade de expressão, que deve ser lastreada por estes valores, principalmente pelos Direitos Humanos, princípio previsto no inciso II, e pela pluralidade e diversidade, previstos no inciso III.

Por si, o princípio da liberdade de expressão asseverado como base do diploma legal aqui analisado também se verifica na Constituição Federal de 88, que garante, no inciso IV do seu Art. $5^{\circ}$, que é livre a manifestação do pensamento, sendo vedado o anonimato. De forma complementar é também previsto, no $\S 2^{\circ}$ do Art. 220 da Carta Magna, que é vedada toda e qualquer censura de natureza política, ideológica e artística, o que contribui para embasar, a partir da absorção deste princípio constitucional pela Lei do Marco Civil, a liberdade da qual goza o usuário do sistema, que pode exprimir livremente seu pensamento, desde que sem extrapolar a seara dos outros princípios previstos tanto no diploma legal quanto no Texto Maior, como o respeito aos Direitos Humanos.

Subsiste, no entanto, um problema na interpretação geral da liberdade de expressão, que é frequentemente confundida com liberdade para se dizer qualquer coisa. Como evidenciado pela redação da Lei, a liberdade de expressão que é basilar para o funcionamento - e até mesmo para a existência - da Internet precisa ser acompanhada pelo respeito aos Direitos Humanos e às diferenças, de forma a manter a rede como um ambiente livre de discursos discriminatórios.

Apesar do necessário sopesamento dos princípios basilares da Constituição, a massificação do acesso à Internet contribuiu para que se proliferassem as páginas e os discursos que violam estes preceitos fundamentais, principalmente pela impressão de impessoalidade e anonimato que muitos sentem no ambiente virtual, onde se consideram livres para expressar discursos indevidos, para caluniar e ofender outros usuários e violar a lei, muitas vezes convictos da certeza da impunidade.

A ampla difusão da Internet e a certeza da impunidade contribuem também para a multiplicação de crimes antes inexistentes, como exemplificado pela Lei 12.737/2012, conhecida como Lei Carolina Dieckmann, que serviu para tipificar uma série de crimes informáticos, principalmente a invasão de dispositivos eletrônicos com o fim de obter, 
adulterar ou destruir dados sem autorização expressa ou tácita do titular do dispositivo ou instalar vulnerabilidade para obter vantagem ilícita.

Outrossim, tais condutas podem trazem uma considerável carga adicional à vítima, principalmente por conta do chamado efeito Streisand: este termo, cunhado pelo digital influencer Mike Masnick, serve para designar os casos - jurídicos ou não - nos quais um fato anônimo ou de pouco alcance, como a instauração de um processo judicial ou a divulgação de uma foto, por exemplo, termina por viralizar na Internet em consequência dos próprios atos do indivíduo envolvido quando ele tenta ocultar ou censurar a situação, gerando uma divulgação ainda maior - e, consequentemente, mais danosa - do fato que o indivíduo em questão tentava esconder. Segundo Hartmann (2018, p.14),

\begin{abstract}
Ao reportar o ocorrido buscando viabilizar a persecução penal do responsável ou a obtenção de indenização por danos morais na seara cível, a pessoa retratada em imagens e vídeos pode acabar chamando mais atenção para o fato e ampliando ainda mais a disseminação da mídia. Assim, ela amplia a lesividade da conduta de que foi vítima. É o fenômeno resultante da velocidade e horizontalidade da disseminação da informação na Internet que foi chamado de "efeito Streisand".
\end{abstract}

A despeito da consagração da liberdade de expressão como princípio basilar do Marco Civil, no entanto, a lei nada diz sobre liberdade de pensamento: em interessante insight, Gonçalves (2017, pp. 11-12) afirma que, ao declarar proteção apenas à liberdade de expressão, não à liberdade de opinião, a Lei 12.965/14 acaba por proteger apenas a expressão pública de opiniões, negligenciando a proteção aos registros e dados particulares dos indivíduos, que seriam, em sentido amplo, pensamentos não-exteriorizados. Dessa forma, o diploma legal estaria restringindo a multidimensionalidade do princípio da liberdade de expressão, que, de acordo com a redação constitucional, pressupõe também a liberdade de pensamento, solapando a proteção da Lei contra possível vigilantismo estatal e contra o uso não-autorizado e irrefreado de dados pessoais por parte de empresas privadas.

Essa questão circunda todo o desenvolvimento da Big Tech, as poderosas companhias de tecnologia do Vale do Silício que construíram grandes impérios tecnológicos e financeiros com base no tratamento e na negociação de dados sigilosos dos usuários, como demonstrado pelo escândalo Facebook-Cambridge Analytica, no qual dados de mais de 80 milhões de usuários da rede social foram cedidos e utilizados sem o seu consentimento pleno entre $2014 \mathrm{e}$ 2018 e, mais recentemente, pelos vazamentos de documentos que revelam que o fundador e CEO do Facebook, Mark Zuckerberg, teria se utilizado indiscriminadamente de dados 
sigilosos dos usuários de sua rede social para negociatas com parceiros, como a Amazon e a Microsoft, além da possível venda destes dados para desenvolvedores de software.

Tais controvérsias tornam-se ainda mais relevantes ao se levar em consideração o número massivo e crescente de usuários de dispositivos conectados à Internet. De acordo com dados recentes divulgados pela gigante da tecnologia Google, mais de 2,5 bilhões de pessoas ao redor do mundo fazem uso do seu sistema operacional, o Android, números dificilmente reconfortantes quando se verifica a imensa quantidade de processos judiciais que a companhia enfrenta, em todo o globo, por questões relacionadas à proteção de dados.

Cabe ressaltar que, no Brasil, no ano de 2016 mais de 90\% dos usuários de celulares dispunham de dispositivos com Android, o que se revela preocupante caso as vulnerabilidades do sistema estejam, de fato, sendo exploradas por companhias e governos inescrupulosos.

A presença massiva dessas companhias no setor de tecnologia, fazendo com que elas se tornem presença praticamente obrigatória no dia-a-dia de qualquer indivíduo neste século, também demonstra a possível vulnerabilidade a qual estão submetidos os usuários, que confiam aos seus dispositivos conectados à Internet os mais variados dados pessoais e íntimos: desde conversas e fotografias privadas até dados bancários, localização em tempo real, segredos pessoais e profissionais, dentre inúmeros outros. A quantidade de dados coletada por estas companhias fica evidente ao se analisar o nível de personalização e refinamento presentes para cada usuário nas buscas em sites e perfis de redes sociais. De acordo com Bauman (2019),

\footnotetext{
Sabe-se razoavelmente bem que pessoas diferentes que consultam a mesma palavra no Google contém resultados diferentes. Isso porque o Google refina seus resultados de buscas segundo as pesquisas anteriores. Da mesma forma, os que têm muitos amigos no Facebook só vão receber atualizações daqueles sobre os quais o próprio Facebook julga que se quer ter notícias, com base na frequência das interações com essas pessoas.
}

Um dos principais problemas oriundos desta imensa mina de dados pessoais que se tornou a Internet, no entanto, não é apenas o uso inescrupuloso destes dados por parte da Big Tech, mas principalmente o uso por parte de governos, o que está deixando transparecer, hoje, uma realidade de ares quase orwellianos. Para alguns autores, hoje vive-se a Era da Vigilância, em muito facilitada pela paranoia coletiva vivenciada após os ataques de 11 de setembro de 2001, que foram instrumentais para a cessão de poderes cada vez maiores às agências de vigilância e espionagem, particularmente nos Estados Unidos. 
Essa postura dos principais Estados do mundo passou a ser mais perceptível e foi trazida à baila após a criação do Wikileaks em 2006, organização dedicada a publicar documentos secretos de Estados, indivíduos e organizações e que ganhou notoriedade após a divulgação, em 2010, de uma série de documentos sigilosos do governo dos Estados Unidos. Os vazamentos deixaram evidente a profundidade da espionagem levada a cabo por agências governamentais, infiltradas nos mais diversos níveis da rede e tendo acesso ao tráfego de dados oriundo de milhões de dispositivos conectados à Internet. De acordo com Julian Assange (2013, p.20-21), o fundador do Wikileaks, "todos os dias, centenas de mensagens vindas de todo o continente latino-americano são devoradas por órgãos de espionagem norteamericanos e armazenadas para sempre em depósitos do tamanho de cidades ”.

O governo chinês também se encontra envolvido em uma série de acusações de invasões a dispositivos, inclusive exportando tecnologia com potencial para uso em espionagem, como revela o banimento recente, em vários países, de dispositivos da companhia chinesa de hardware Huawei, acusada de trabalhar em conjunto com agências de espionagem de seu país de origem. Para além disso, é fato notório a forte vigilância do governo chinês sobre seus cidadãos, de forma a observar e controlar praticamente todos os momentos e todos os aspectos da vida dos indivíduos, principalmente nos grandes centros urbanos do país.

A questão dos dados e de sua proteção é, portanto, um dos grandes debates da atualidade e um dos principais problemas, no Brasil, do Marco Civil da Internet, que não parece oferecer solução efetiva para a proteção de dados dos usuários, o que contribui para uma vulnerabilidade ainda maior do usuário brasileiro, que, além de ter seus dados escrutinizados pelas agências de espionagem nacionais e estrangeiras, não possui proteção legal que possa ser reivindicada. Segundo o relatório Um Novo Mundo de Dados, do Grupo de Ensino e Pesquisa em Inovação da Fundação Getúlio Vargas, apesar de o Marco Civil fazer referência à proteção de dados, não estabelece os termos nos quais essa proteção deve se dar, o que resulta em um vácuo regulatório que torna premente a redação de uma lei geral que trate e regule especificamente o assunto (FGV,2017, p.11).

Essa falta de proteção evidencia que a Lei não absorveu, da Constituição Federal, as garantias constantes nos incisos X e XII do Art. $5^{\circ}$, que declaram a inviolabilidade da vida privada e do sigilo de correspondências e dados. Enquanto o diploma legal revela a preocupação do legislador com a proteção do usuário como consumidor de planos de Internet, não trata adequadamente da proteção aos dados deste usuário, questão que ainda se encontra em uma zona cinzenta do ordenamento. 
Além das necessidades emanadas da Constituição, o Direito brasileiro também deve fazer força para acompanhar os desenvolvimentos globais nessa seara, principalmente porque a Internet não é fenômeno localizado, mas sim global, e as companhias que estão fazendo uso de dados dos usuários brasileiros são, majoritariamente, econômicas e internacionais. Segundo Sundfeld (2014, p.284-285),

\begin{abstract}
A impelir o Estado a criar novas regulações - algumas surpreendentes - está justamente uma série de pressões de origem externa; não constrangimentos jurídicos, mas essencialmente econômicos. (...). Ao conceber e aplicar suas normas - e aqui está o ponto - o Estado passa a fazê-lo em função das necessidades mundiais de organização da vida econômica, social e política; mais ainda, essas imposições tornam-se determinantes da própria dimensão do Estado, da profundidade de suas intervenções, do limite de seus poderes.
\end{abstract}

Possível tratamento para esse problema, ainda que de forma simbólica e necessitando de debates sobre viabilidade e aplicabilidade, é a Proposta de Emenda à Constituição $\mathrm{n}^{\circ} 17 / 2019$, de autoria do senador Eduardo Gomes (MDB/TO), que visa a acrescentar à Constituição, como direito fundamental do cidadão, a proteção de dados pessoais, inclusive e principalmente - nos meios digitais. Enviada à Câmara dos Deputados em julho de 2019, a proposta aguarda análise por aquela casa e ainda não tem previsão de ir à votação.

O impacto destas questões na seara administrativa se verifica na medida em que essas demandas locais e globais passam a influenciar as cadeias de normas nacionais, principalmente sob pressão da economia mundial, de forma a reorganizar a estrutura administrativa do Estado, a partir do qual emanarão novas regulações voltadas a normatizar as inovações absorvidas pelo país (SUNDFELD, 2014). Essa absorção de novos elementos influencia, também, no surgimento de novas interpretações e possibilidades para os princípios do direito administrativo, que tem demonstrado capacidade de adaptação às novidades que vêm rejuvenescendo as discussões no direito brasileiro.

O princípio da abertura, previsto no inciso IV do Art. $2^{\circ}$ da Lei do Marco Civil da Internet, pode ser interpretado de forma ampla como paralelo ao princípio da transparência ou publicidade -, valor basilar para o direito administrativo. Segundo este princípio, cabe à Administração dar publicidade de seus atos, contratos e instrumentos jurídicos, de forma a dar transparência a todas as operações que acontecem no interior da estrutura pública e possibilitar, ao cidadão, o controle, o escrutínio e o questionamento de quaisquer atos da Administração.

Ao prever este princípio no diploma legal, o legislador aparenta ter seguido a racionalidade de busca por uma regulação que não subtraísse, da internet, o seu caráter aberto 
e público. Ao assumir essa postura, parece, no entanto, ter caído em outra controvérsia: ao apenas prever um princípio da Administração, sem normas de aplicação à realidade fática, não ponderou sobre como o Marco Civil seria efetivamente aplicado pelo - e ao - Direito Administrativo. Existiria, segundo Varella (2018, p.516), uma "vagueza dos princípios constitucionais de publicidade e privacidade, pois a matéria ainda sofre com a ausência de legislação específica para regulamentá-la, como é o caso dos dados pessoais e sensíveis'”.

Essa vagueza enseja, na prática, em conflito entre princípios constitucionais, com o dever de publicidade se opondo ao direito à privacidade, ainda que o primeiro possa ser entendido como questão de ordem e interesse público, devendo se sobrepor, caso necessário na realidade fática, ao segundo.

Nesse sentido, tendo um dever de transparência que agora pode (e deve) se concretizar também na Internet, em consonância com os tempos e com o crescente número de brasileiros com acesso à rede, a Administração se depara também com a dificuldade de lidar de forma aberta e transparente com dados sensíveis, o que se revela sempre um desafio para uma estrutura acostumada - principalmente no Brasil - a agir dentro de campos opacos, escassos em accountability. ${ }^{4}$

Sendo assim, a despeito de a regulamentação da rede ter trazido, em seu bojo, o princípio da publicidade da Administração, revelando a intenção, por parte do legislador, de conciliar a atuação nas duas esferas, a falta de legislação específica dificulta este trabalho conjunto, ainda que, desde a massificação da internet, os órgãos públicos tenham feito esforços para publicizar cada vez mais os seus atos através da rede, seguindo uma política de publicidade ampla.

Um fundamento constitucional da ordem econômica prestigiado pela Lei do Marco Civil é o da liberdade de iniciativa, que se encontra previsto no inciso V do Art. $2^{\circ}$ da Lei. Se o princípio da Publicidade aproxima o Direito Administrativo do dispositivo legal, a liberdade de iniciativa o afasta, em defesa da noção de que não cabe, à Administração, a interferência nas atividades econômicas legais desempenhadas por particulares, inclusive no âmbito da Internet. Sendo assim, na rede, como no mundo físico, é assegurado a todos o livre exercício de qualquer atividade econômica, independentemente de autorização de órgãos públicos, como consta no Art. 170 da Constituição Federal, devendo a Administração possibilitar este exercício sem excessivas amarras burocráticas, lhe cabendo, como determinado pelo Art. 174 da Carta Magna, as funções de fiscalização, incentivo e planejamento de forma determinante

\footnotetext{
4 Transparência.
} 
somente para o poder público, mas não para o privado, que possui a prerrogativa de acatar tais recomendações de forma apenas indicativa. Segundo Bandeira de Mello (2017, p.847),

(...) o Estado não pode impor aos particulares nem mesmo o atendimento às diretrizes ou intenções pretendidas, mas apenas incentivar, atrair os particulares, mediante planejamento indicativo que se apresente como sedutor para condicionar a atuação da iniciativa privada.

Por outro lado, a Administração Pública tem papel relevante no que tange à limitação da iniciativa privada, que também deve ser guiada pelos valores fundamentais que erigiram o ordenamento jurídico, tais como a dignidade da pessoa humana, que "constitui fim último da ordem econômica nacional, razão pela qual pode se afirmar que é dever de todos, solidariamente"(BERTONCINI, 2013, p.194).

\section{CONSIDERAÇÕES FINAIS}

A encruzilhada na qual se encontra a Administração Pública é etapa essencial para o futuro: as novidades do admirável mundo novo da Internet precisam ser incorporadas e aproveitadas pela estrutura do Estado, porém de forma positiva, utilizando as novas ferramentas a favor dos interesses coletivos da população e refletindo os princípios que construíram o ordenamento jurídico nacional, promovendo, com o auxílio da rede, os direitos da população e preservando a dignidade da pessoa humana. A controvérsia do uso desmedido de dados privados por parte de companhias e Estados é questão longe de alcançar decisão definitiva, justamente por tratar de caso de colisão de princípios: deve prevalecer o interesse coletivo ou o direito à privacidade? Como ensina Alexy - e, de forma mais longínqua, Aristóteles, com seu caminho do meio - cabe ao legislador encontrar a justa medida entre os dois princípios, de forma a não prescindir de nenhum deles.

O caminho inaugurado pelo Marco Civil da Internet ainda necessita de refinamentos e debates, sendo a Lei em si uma ferramenta profundamente principiológica, que carece, em geral, de meios mais evidentes de aplicabilidade à realidade. A despeito dessa impotência da Lei, no entanto, o diploma legal foi um passo positivo rumo ao futuro, pois inaugurou, no Brasil, um caminho de medidas amplas por parte do Poder Legislativo para regular - e, ainda que pareça adverso, promover - a utilização da internet no Brasil, medidas que, assim como a Lei Carolina Dieckmann, representam um avanço considerável em um cenário que, até então, era desoladoramente vazio. 
A absorção e a efetiva aplicabilidade dos princípios administrativos e constitucionais por parte da legislação infraconstitucional que eventualmente surgir a partir destes avanços no campo da internet será árdua, dado o arcaísmo que permeia muitos dos setores da Administração, porém, apesar de seus problemas, o Marco Civil foi capaz de apontar um caminho para o futuro. Assim como para Huxley, as máquinas têm de continuar girando, mas para isso é imprescindível a estabilidade da lei.

\section{REFERÊNCIAS}

ALEXY, Robert. Teoria dos Direitos Fundamentais. 2ªd. São Paulo: Malheiros, 2014.

ASSANGE, Julian. Cypherpunks: liberdade e o futuro da internet. Tradução de Cristina Yamagami. São Paulo: Boitempo, 2013.

AZEVEDO, Floriano de. Os grandes desafios do controle da Administração Pública. In: modesto, Paulo (org.).Nova Organização Administrativa Brasileira. Belo Horizonte: Editora Fórum, 2010.

BARLOW, John Perry. A Declaration of the Independence of Cyberspace. Disponível

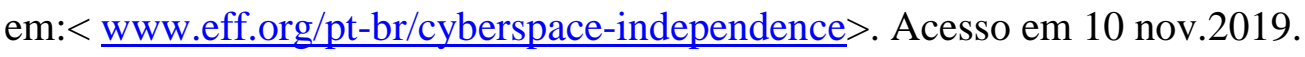

BAUMAN, Zygmunt. Vigilância Líquida: diálogos com David Lyon/Zygmunt Bauman. Tradução de Carlos Alberto Medeiros. Rio de Janeiro: Zahar, 2013.

OLHAR DIGITAL. Mark Zuckerberg se aproveitou de dados de usuários do Facebook, revelam documentos. Disponível em: <https://olhardigital.com.br/noticia/markzuckerberg-se-aproveitou-de-dados-de-usuarios-do-facebook-revelam-documentos/92639. Acesso em 13 nov.2019.> Acesso em: 24 mar. 2020.

BERTONCINI, Mateus. PORTELLA JUNIOR, José Carlos. A responsabilidade social da empresa e a erradicação do trabalho escravo. In: Pensar, Fortaleza, v.18, nº1, pp.190-209, jan./abr. 2013. 
BONAVIDES, Paulo. Do Estado liberal ao Estado social. 9. ed. São Paulo: Malheiros, 2009.

DRAGO, Pedro Anibal; lEVY, Evelyn (Orgs.). Gestão Pública no Brasil Contemporâneo. São Paulo: Editora FuNDAP, 2005.

FGV São Paulo. Um Novo Mundo de Dados: relatório final do Projeto de Pesquisa Aplicada do Grupo de Pesquisa e Ensino em Inovação. São Paulo: FGV Direito, 2017.

GABARDO, Emerson. Interesse público e subsidiariedade: o Estado e a sociedade civil para além do bem e do mal. Belo Horizonte: Fórum, 2009.

GIDDENS, Anthony. Mundo em descontrole: o que a globalização está fazendo de nós. Rio de Janeiro: Record, 2000.

GONÇALVES, Victor Hugo Pereira. Marco Civil da Internet Comentado. $1^{\text {a } e d . ~ S a ̃ o ~ P a u l o: ~}$ Editora Atlas, 2017.

GRAU, Eros. A ordem econômica na Constituição de 1988: interpretação e crítica. 8. ed. São Paulo: Malheiros, 2003.

HARTMANN, Ivar A. Regulação da Internet e novos desafios da proteção de direitos constitucionais: o caso do revenge porn. In: RIL Brasília a. 55 n. 219 jul./set. 2018 p. 13-26.

HENRIQUE, Lygia Maria Moreno Molina. Neutralidade da Rede e Impactos na Relação de Consumo, p.5. Disponível em: <https://www.pucsp.br/tutelacoletiva/download/neutralidade_de_rede_e_os_impactos_na_rel acao_de_consumo.pdf. Acesso em 15/11/2019>. Acesso em: 15 nov.2019.

HUXLEY, Aldous. Admirável Mundo Novo. $22^{a}$ ed. São Paulo: Globo, 1996, p.43.

MELLO, Celso Antônio Bandeira de. Curso de Direito Administrativo. 34aaed. São Paulo: Malheiros, 2017. 
MOREIRA NETO, Diogo de Figueiredo. Reflexões sobre a transformação do estado moderno (desdobramentos de uma análise juspolítica). In: Poder, direito e estado: o direito administrativo em tempos de globalização - in memoriam de Marcos Juruena Villela Souto. Belo Horizonte: Fórum, 2011.

MOREIRA, Vital. A ordem jurídica do capitalismo. 3. ed. Coimbra: Centelha, 1978.

MUÑOZ, Jaime Rodríguez-Arana. Direito fundamental à boa administração pública. Trad. Daniel Wunder Hachem. Belo Horizonte: Fórum, 2012.

LEMOS, Ronaldo. Internet Brasileira Precisa de Marco Regulatório Civil. 2007. Disponível em: https://tecnologia.uol.com.br/ultnot/2007/05/22/ult4213u98.jhtm. Acesso em 08 nov.2019.

SOUZA, Carlos Affonso. Marco Civil da Internet: construção e aplicação. Juiz de Fora: Editar Editora, 2016, p.16.

LEMOS, Ronaldo. SOUZA, Carlos Affonso. Marco Civil da Internet: construção e aplicação. Juiz de Fora: Editar Editora, 2016.

PETTER, Lafayete Josué. Princípios constitucionais da ordem econômica: o significado e o alcance do art. 170 da Constituição Federal. 2. ed. São Paulo: Revista dos Tribunais, 2008 .

Sabino Cassese. Le Basi dei Diritto Amministrativo. Milão, Garzanto, 2000, $5^{\text {a }}$ edição, p. 120.

SALOMÃO FILHO, Calixto. Regulação da atividade econômica: princípios e fundamentos jurídicos. 2. ed. São Paulo: Malheiros, 2008.

SEN, Amartya. Desenvolvimento como liberdade. São Paulo: Companhia das Letras, 2000.

SIRAQUE, Vanderlei. O controle social da função administrativa do Estado: possibilidades e limites na Constituição de 1988. 2004. Dissertação (Mestrado) - Pontifícia Universidade Católica de São Paulo. 
SUNDFELD, Carlos Ari. Direito Administrativo para Céticos. $2^{\mathrm{a} e d . ~ S a ̃ o ~ P a u l o: ~ M a l h e i r o s, ~}$ 2014.

VARELLA, Marcelo D. GONÇALVES, Tânia Carolina Nunes Machado. Os desafios da Administração Pública na disponibilização de dados sensíveis. In: Revista Direito FGV, v.14, pp.513-536, mai./ago. 2018.

VIANA, Ana Cristina Aguilar. KREUZ, Letícia Regina Camargo. Admirável Mundo Novo: a Administração Pública do século XXI e as tecnologias disruptivas. In: Int. Públ. - IP, Belo Horizonte, ano 20, n. 110, pp. 51-68, jul./ago. 2018.

VILLATORE, Marco Antônio César; GUNTHER, Luiz Eduardo. GLOBALIZATION, ECONOMIC CRISIS AND COLLECTIVE BARGAINING IN INTERNATIONAL LABOR LAW. Revista Juridica, [S.1.], v. 51, n. 2, p. 137 - 165, abr. 2018. ISSN 2316-753X. Disponível em: $<$ http://revista.unicuritiba.edu.br/index.php/RevJur/article/view/2803/371371471>. Acesso em: 20 abr. 2020. doi:http://dx.doi.org/10.21902/revistajur.2316-753X.v51i2.2803.

WU, Tim. Network Neutrality, Broadband Discrimination. In: Vol 2, Journal on Telecommunications and Hogh Technology Law, 2003. Disponível em: <http://www.jthtl.org/content/articles/V2I1/JTHTLv2i1_Wu.PDF>. Acesso em 19 nov. 2019. 